\title{
Mitigation of saturation in satellite pasture measurement via incorporation of a statistical pasture growth model
}

\author{
Grant ANDERSON ${ }^{1, *}$, Mitchell RAWLINGS ${ }^{1}$ and Graeme OGLE ${ }^{2}$ \\ ${ }^{1}$ Livestock Improvement Corporation, Private Bag 3016, Hamilton, New Zealand \\ ${ }^{2}$ Rezare Systems Limited, PO Box 9466, Hamilton, New Zealand \\ *Corresponding author: grant.anderson@lic.co.nz
}

\begin{abstract}
Measurement of pasture biomass is useful to farmers, as it enables timely and accurate management decisions. Satellite pasture measurement allows this information to be obtained with minimal time and labour on the part of the farmer. However, the accuracy of satellite measurements for high levels of pasture biomass can be impacted by a phenomenon called saturation, in which the response of the satellite estimate to increased biomass is diminished in situations of high biomass. In this investigation, a statistical pasture growth model was combined with satellite pasture measurements, with the aim of mitigating the effect of saturation on estimation accuracy. Data were captured for five farms, across two regions and an 18-21 month measurement period. Where satellite measurements appeared to be saturated, the growth model estimate was substituted. This process resulted in improved accuracy $\left(\mathrm{R}^{2}\right.$ improved from 0.672 to 0.703 ; RMSE improved from 334 to $309 \mathrm{~kg} \mathrm{DM} / \mathrm{ha}$; and average bias improved from -62 to $-9 \mathrm{~kg} \mathrm{DM} / \mathrm{ha}$ ). The statistical improvements were more pronounced where terrestrial estimates were higher so the impact of saturation would be greatest. These results indicate that the problem of saturation in satellite pasture measurement can be addressed by the incorporation of modelled data.

Prior research has predicted that improved accuracy of pasture measurement would be associated with increased profitability, and this work helps achieve that goal for farmers using satellite measurement services.
\end{abstract}

Keywords: Pasture management, pasture cover, pasture growth modelling

\section{Introduction}

In a pastoral farming system, as used in most New Zealand farms, a substantial amount of on-farm value can be gained from better pasture management. To make optimal management decisions, the pasture biomass should be regularly measured (Eastwood \& Dela Rue 2017). Modelling work has indicated that approximately $\$ 385 /$ ha can be gained with use of imperfect knowledge of pasture biomass (average 15\% error), relative to naïvely selecting the paddock that was grazed least recently, and that a further $\$ 155 /$ ha could be achieved with use of perfect knowledge of paddock biomass (Beukes et al. 2019).

However, conventional methods for measuring pasture - such as rising plate meters, visual assessment, and the C-DAX Pasture Meter - are relatively expensive in terms of time and effort, and also subject to operator error (Chapman et al. 2014).

These problems may be addressed by satellite-based pasture estimation, using vegetation indices based on spectral data transmitted from the orbital platforms (Ali et al. 2016). Satellite estimation requires no time investment nor effort by the farmer, allowing that effort to be invested in making use of the information. There is generally a financial cost to acquire the information, which can be weighed up against the cost of the labour that would be required for human measurement, and the availability of that labour at certain times during the dairy season. Satellite estimation is not subject to operator error as a rising plate meter is. However, satellite pasture biomass estimation has challenges of its own (Mata et al. 2011). This investigation focuses on saturation, but the slope of the pasture, cloud, and cast shadows are other issues that need to be dealt with in the course of satellite estimation.

Satellite vegetation indices can be affected by saturation in the spectral bands they utilise (Huete et al. 1997). In such cases, increases in biomass no longer result in increases in the indices. In the case of pasture estimation, this results in underestimation, which can be observed as a negative bias relative to terrestrial measurements. This saturation can be somewhat mitigated by applying an adjustment to the index (Gu et al. 2013), or addressed by the use of more precise spectral bands (Mutanga \& Skidmore 2004). However, the availability of such narrow spectral bands is a function of satellite hardware, rather than how the satellite data are processed, and is thus dependent on the satellite imagery provider, rather than post-processing calculations.

One possible solution to the impact of saturation in a satellite-based pasture estimation system where the satellite hardware cannot be modified is to augment the system with data from a source that is independent of the satellite hardware. As described above, there are many methods for pasture estimation, but most of 
these would require time and effort from the farmer, thus reducing the value of satellite-based estimation. However, pasture growth can be estimated with pasture growth models (Woodward \& Rollo 2002), and this does not require input from the farmer. The Rezare Pasture Growth Forecaster Service (PGF) uses the DairyNZ pasture growth model developed from the Pasture Growth Simulator Using Smalltalk (PGSUS) system (Romera et al. 2013), and is a commercial pasture growth model serving a number of businesses. It utilises information about a farm's type (dairy, sheep and beef on high fertility soil, or sheep and beef on low fertility soil) and geographical location, as well as the level of plant available water (PAW) in the soil, climate data (such as rain, temperature, solar radiation and evapotranspiration) and inputs such as irrigation and nitrogen to predict the amount of daily change (whether increase or decrease) in biomass. Unlike satellite estimation, it is not interfered with by atmospheric conditions. However, the PGF can only produce biomass predictions if biomass estimates are supplied (whether these be from the farmer or a satellite), to which its growth estimates can be applied. Additionally, without regular measurement information, the model will not incorporate any changes that occur due to grazing, or other impacts on pasture apart from weather.

The aim of this project was to investigate to what extent the Rezare PGF could be used alleviate the impacts of saturation on satellite pasture estimation accuracy. Pasture estimates from a system combining satellite and PGF information, and a system using wholly satellite information, were evaluated by comparison to manual terrestrial pasture estimates.

Such a system would theoretically capture the best points of both its components; the satellite imagery could provide regular biomass estimates to provide a base for the growth model, and the growth model could provide biomass estimates when the satellite system was impacted by saturation. Initial validation of the LIC SPACE ${ }^{\mathrm{TM}}$ system (LIC 2020) showed a standard deviation of error of $329 \mathrm{~kg} \mathrm{DM} / \mathrm{ha}$ for satellite measurement, within the range of accuracy reported for the rising plate meter (Anderson \& McNaughton 2018).

If the resulting system successfully addressed the challenges that satellite-based measurement systems can face with band saturation, it would enable delivery of more accurate pasture assessments to farmers, which would in turn enable timelier and more accurate grazing management decisions.

\section{Materials and Methods Study locations}

The datasets for this investigation consisted of satellite records and farmer measurements from five farms, generally flat, located in the Waikato (farms B and
D) and Canterbury (farms A, C, and E) regions of New Zealand. Farms A, C and E were all assessed by the same trained plate meter operator. Farm B was assessed by a trained plate meter operator. Farm D was visually assessed by trained farm staff. All of the farms had predominantly perennial ryegrass-white clover pastures, and the paddock sizes ranged from 0.35 to 6.24 hectares.

\section{Terrestrial data collection}

Terrestrial biomass estimates were obtained from all five farms in the study. In most cases, these were from rising plate meter measurements, performed by farm staff or other rural professionals. In the case of one farm, they were the result of visual assessments performed by trained farm staff. The number of biomass assessments that were available for each farm within the period of the investigation varied among farms (Table 1).

\section{Satellite imagery collection}

All available satellite images were obtained during the study from Planet's constellation of Dove satellites (Planet 2020) and the European Space Agency's Sentinel-2 satellites. The Dove constellation consists of more than 130 satellites, each belonging to one of three models (Table 2). These images were corrected by Planet for surface reflectance (Planet 2018) to remove atmospheric artefacts, making the images more comparable across time, and across satellites. The Sentinel-2 images were similarly corrected (ESA 2020). The initial dataset contained 434 whole-farm images, of which 138 occurred within one day of a terrestrial assessment. Only images that were approved for sending to customers of the LIC SPACE ${ }^{\mathrm{TM}}$ product were used in this analysis. For each of the paddocks in each image, the timestamp of the image, an estimate of cloud cover, and the satellite identifier were supplied to us, and the mean red, green, blue (RGB) and nearinfrared (NIR) reflectance were computed. The LIC $\mathrm{SPACE}^{\mathrm{TM}}$ algorithm was applied to transform these reflectance values into biomass estimates.

Biomass estimates where the Planet cloud algorithm reported non-zero cloud cover were discarded, as were estimates where visual inspection of an image identified cloud, or any other anomaly that could impact satellite measurement. The methods currently available for automatic filtering of images are imperfect so manual data processing is still necessary to generate a clean dataset. We hope to refine these in the future. For example, during a drought event, where the dry matter in the paddock is dead, biomass estimation incorporating photosynthesis estimation via NIR emission will underestimate dry matter. (This error, like saturation, is a systematic problem with satellite estimation, and could potentially be amenable to a similar approach but has 
Table 1 Quantity and collection method of biomass assessments and satellite images within one day of biomass assessments, number of paddocks, size of farm, and period of investigation, by trial farm.

\begin{tabular}{|c|c|c|c|c|c|c|c|}
\hline \multirow{2}{*}{$\begin{array}{l}\text { Farm } \\
\text { A }\end{array}$} & \multicolumn{2}{|c|}{$\begin{array}{c}\text { Terrestrial } \\
\text { assessments }\end{array}$} & \multirow{2}{*}{$\begin{array}{c}\text { Satellite images } \\
\text { within one day } \\
\text { of assessment }\end{array}$} & \multirow{2}{*}{$\begin{array}{c}\text { Number of } \\
\text { paddocks }\end{array}$} & \multirow{2}{*}{$\begin{array}{c}\begin{array}{c}\text { Farm size } \\
\text { (ha) }\end{array} \\
76\end{array}$} & \multirow{2}{*}{$\begin{array}{l}\text { Start date } \\
6 \text { Jul } 2018\end{array}$} & \multirow{2}{*}{\begin{tabular}{|c|} 
End date \\
31 Jan 2020
\end{tabular}} \\
\hline & RPM & 64 & & & & & \\
\hline B & RPM & 63 & 30 & 66 & 141 & 27 Jun 2018 & 31 Jan 2020 \\
\hline C & RPM & 68 & 27 & 42 & 104 & 4 Jul 2018 & 29 Jan 2020 \\
\hline D & Visual & 107 & 38 & 119 & 129 & 3 Jul 2018 & 2 Apr 2020 \\
\hline$E$ & RPM & 39 & 14 & 50 & 280 & 3 Sep 2018 & 7 Jan 2020 \\
\hline
\end{tabular}

Table 2 Spectral band ranges for the Planet satellites from which images were acquired.

\begin{tabular}{lcccc}
\hline & \multicolumn{2}{c}{ Spectral bands (nm) } \\
\cline { 2 - 5 } Model & Blue & Green & Red & Near-infrared (NIR) \\
\hline ps2 & $455.0-515.0$ & $500.0-590.0$ & $590.0-670.0$ & $780.0-860.0$ \\
ps2.sd & $464.0-517.0$ & $547.0-585.0$ & $650.0-682.0$ & $846.0-888.0$ \\
psb.sd & $457.5-522.5$ & $542.0-577.5$ & $650.0-680.0$ & $697.5-712.5$ \\
\hline
\end{tabular}

not yet been investigated). Estimates for paddocks that were grazed in the time between the on-ground and satellite measurements were also manually noted and removed. Note that this is only a problem when evaluating the accuracy of the estimations, to ascertain that both measurement methods are measuring the same paddock at approximately the same biomass level; in general use, the timing of other pasture measures would be irrelevant. The final number of satellite estimates was 2611 .

\section{Saturation detection}

Predictions from the Rezare PGF were used to identify pasture biomass estimates that were affected by saturation (hereafter saturated). For a particular satellite image, a paddock could be assigned to either Satellite mode (the satellite estimate should be used) or Model mode (the paddock was believed to be saturated and the PGF estimate should be used). Once a paddock was in Model mode, it would only return to Satellite mode if it had a satellite biomass reading under $2400 \mathrm{~kg} \mathrm{DM} /$ ha; this number was lower than the saturation minimum to allow for a small amount of measurement error in satellite estimates. A value of $2500 \mathrm{~kg} \mathrm{DM} / \mathrm{ha}$ was selected as the minimum to consider for a transition to Model mode; this was a conservative estimate based on a preference for erroneously using modelled results compared to failing to detect saturation. An allowance was made, based on inspection of the data, for the difference permitted between the satellite and model estimates to increase slightly with the number of days since the most recent satellite estimate (Table 3).

To determine the paddock mode (either Satellite or Model, as described above) for a given satellite image:

1. Get satellite biomass estimate

2. If satellite biomass estimate $>2500 \mathrm{~kg} \mathrm{DM} / \mathrm{ha}$, potentially saturated, go to 3 ; otherwise go to 6

3 . Based on the number of days since the last image, obtain a saturation threshold (Table 3)

4. Get PGF biomass estimate

5. If (PGF biomass estimate - satellite biomass estimate) is greater than the saturation threshold, set paddock mode to Model; END

6. If satellite biomass estimate $<2400 \mathrm{~kg} \mathrm{DM} / \mathrm{ha}$, set paddock mode to Satellite; END.

7. Paddock mode is not changed. END

\section{Dataset construction}

The PGF model can be tailored to individual paddock characteristics. If training data for a paddock in the form of dry matter estimates is added into the PGF model then the parameters of the model can be tuned to capture the growth behaviour of that paddock. For this purpose, each farm's satellite measurements were split into two sets: one for training the model, and one for testing the output. The split was chronological, so that the training records all occurred before the test ones. The first third (chronologically) of the data for each farm was used to train the learning system, and the following two thirds was used for testing. In practice, 
Table 3 Thresholds for satellite image saturation based on decrease relative to growth model predictions.

\begin{tabular}{cc}
\hline $\begin{array}{c}\text { Days since } \\
\text { last used image }\end{array}$ & $\begin{array}{c}\text { Threshold for saturation } \\
\text { (kgDM/ha) }\end{array}$ \\
\hline 1 & 25 \\
2 & 50 \\
3 & 75 \\
4 & 85 \\
5 & 95 \\
6 & 110 \\
7 & 120 \\
8 & 130 \\
9 & 140 \\
10 & 150 \\
11 & 160 \\
12 & 170 \\
13 & 180 \\
14 & 190 \\
\hline
\end{tabular}

a new farm would be set up with past data, and would need to have its parameters tuned for future estimation.

A composite model was generated from a combination of satellite and PGF information, using satellite biomass estimates for each paddock image where the paddock mode was Satellite, and PGF model estimates where the paddock mode was Model. This composite model (Composite) and the satellite (wholly satellite estimates) model (Satellite) were matched against any terrestrial records that occurred within one day of their collection. This provided matched Composite, Satellite, and terrestrial records. An additional subset of the data was produced for terrestrial records over $2500 \mathrm{~kg} \mathrm{DM} /$ ha, for a total of four sets of estimates (Table 4) as this is the level at which we have observed saturation beginning to manifest in the past.

For each set of satellite-based estimates (Composite, Satellite, Composite-high and Satellite-high), the mean error, standard deviation of error, $\mathrm{R}^{2}$, and RMSE between that set of estimates and the terrestrial estimates were computed, overall and for each farm. Note that error, in this context, is the difference between the terrestrial estimate and the estimate to which it is being compared. These statistics were computed across all farms, and for each individual farm.

\section{Results}

The amount of dry matter estimated using terrestrial methods was compared with that estimated using satellite-only data (Figure 1). Overall, the satellite-only data underestimated dry matter by $62 \mathrm{~kg} \mathrm{DM} / \mathrm{ha}$. The composite model replaced 441 (16.9\%) of the 2611 satellite biomass estimates with PGF-derived statistical estimates (Figure 2), and resulted in an improvement in estimating dry matter relative to the terrestrial methods.

By all of the statistics examined, across all farms, the composite-model dataset (Composite) performed better than the satellite-only dataset (Satellite) (Table 5). The relationship between the datasets restricted to terrestrial estimate values greater than $2500 \mathrm{~kg} \mathrm{DM} / \mathrm{ha}$ (Composite-high and Satellite-high) was similar, with the exception that the standard deviation of error was smaller for Satellite-high than for Composite-high.

The model goodness-of-fit results for individual farms were similar to the results for the combined data sets (Table 6). There was a positive shift in bias across all farms. In one of the farms, this resulted in an overall bias slightly further away from zero, while the bias for the remaining farms was closer to zero for the Composite dataset than for the Satellite-only dataset. The RMSE and $\mathrm{R}^{2}$ for the Composite datasets (both Composite and Composite-high) were lower and higher respectively than their Satellite counterparts. As with the all-farm results, the standard deviation of error was smaller for the Composite dataset than the Satellite one for the full dataset. For four of the five farms, the standard deviation of error for Satellite-high was slightly smaller than for Composite-high.

The slope of a simple linear model with Satellite dry matter estimate as the dependent variable, and terrestrial dry matter estimate as the explanatory variable, was 0.60 . The corresponding slope for a model with Composite dry matter estimate as the dependent variable was 0.73 .

The median dry matter estimate was the same for the Satellite and Composite datasets, but the distribution of the Composite estimates had a wider spread, with

Table 4 Composition and count of evaluation data, by Pasture Growth Forecaster inclusion and terrestrial data range.

\begin{tabular}{llcc}
\hline Estimate & Satellite estimation data & Terrestrial estimates & $\mathbf{n}$ \\
\hline Composite & Saturated estimates replaced by PGF & All & 2611 \\
Satellite & Satellite data only & All & 2611 \\
Composite-high & Saturated estimates replaced by PGF & $>2500 \mathrm{~kg} \mathrm{DM} / \mathrm{ha}$ only & 949 \\
Satellite-high & Satellite data only & $>2500 \mathrm{~kg} \mathrm{DM} / \mathrm{ha}$ only & 949 \\
\hline
\end{tabular}




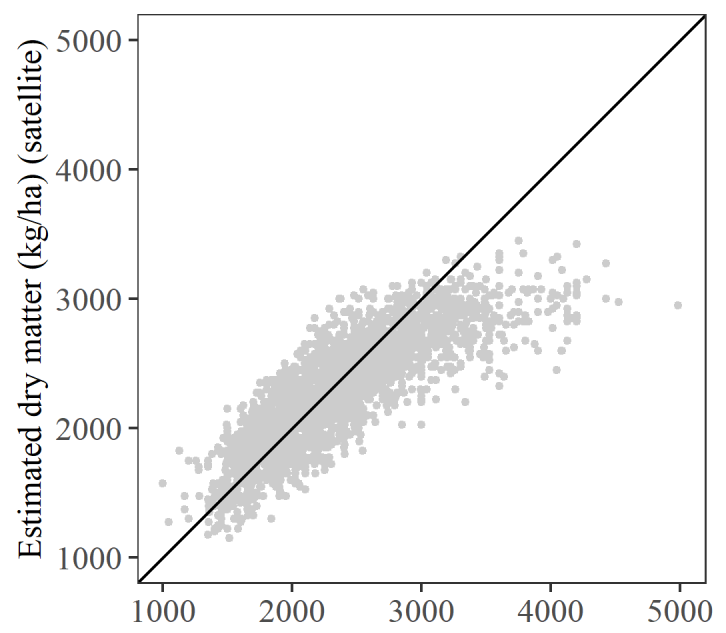

Estimated dry matter $(\mathrm{kg} / \mathrm{ha})$ (terrestrial)

\section{Satellite}

Figure 1 Comparison of terrestrial estimates to wholly Satellite estimates across all farms. Single black line is the line of equality.

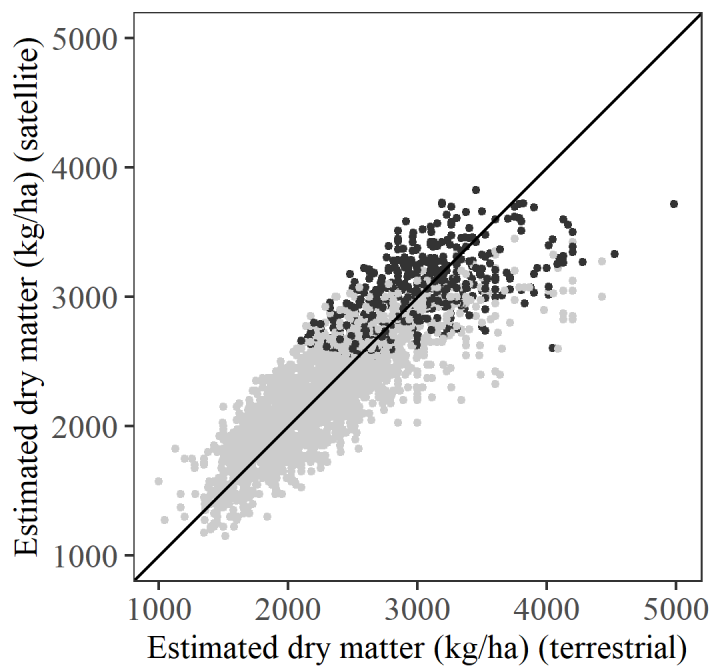

- Composite Satellite

Figure 2 Comparison of terrestrial estimates to Composite estimates across all farms. Single black line is the line of equality.

Table 5 Mean error (bias), standard deviation of error, $\mathrm{R}^{2}$ and RMSE for Composite and Satellite estimates relative to terrestrial estimates, across all data.

\begin{tabular}{lccccc}
\hline Dataset & Count & Mean error & Standard deviation of error & R $^{2}$ & RMSE \\
\hline Satellite & 2611 & -62 & 328 & 0.672 & 334 \\
Composite & 2611 & -9 & 309 & 0.703 & 309 \\
Satellite-high & 949 & -296 & 339 & 0.288 & 450 \\
Compostie-high & 949 & -160 & 355 & 0.323 & 389 \\
\hline
\end{tabular}

a longer upper tail, indicating that the distribution of lower results remained similar, but the Composite system produced higher dry matter estimates (Figure 3).

\section{Discussion}

The incorporation of the growth model into the satellite estimation for data points that were identified as saturated (the Composite estimates) showed improved performance relative to the baseline Satellite performance. The bias, standard deviation of error, and RMSE were smaller, and the $\mathrm{R}^{2}$ was larger.

When the comparison was restricted to only those points that could potentially be saturated (terrestrial estimate of $2500 \mathrm{~kg} \mathrm{DM} / \mathrm{ha}$ or greater), the same relationship held for bias, RMSE, and $\mathrm{R}^{2}$. However, the standard deviation of error was slightly greater for the Composite-high dataset than for the Satellite-high dataset (355 kg DM/ha compared to $339 \mathrm{~kg} \mathrm{DM} / \mathrm{ha}$ ). Three of the five farms also displayed this behaviour when examined individually. One possible explanation for this is that the saturation effect itself is the source of reduced variance around the mean error in the Satellitehigh dataset. The effect of saturation is to restrict the range of possible values, which functionally imposes an upper boundary on estimates. Therefore, the variation in the measurement range of the saturated estimates themselves becomes smaller (standard deviation 362 $\mathrm{kg} \mathrm{DM} / \mathrm{ha}$ and $256 \mathrm{~kg} \mathrm{DM} / \mathrm{ha}$ for Composite-high and Satellite-high estimates respectively, compared to a standard deviation of $399 \mathrm{~kg} \mathrm{DM} / \mathrm{ha}$ in the terrestrial estimates).

The greater $\mathrm{R}^{2}$ displayed by the Composite dataset (relative to Satellite) indicates a stronger linear relationship with the ground truth data, while the reduced bias (particularly for high ground truth values) shows a reduction in the saturation effect. It can be seen that a negative bias still exists in the Composite-high dataset (though substantially smaller than in Satellite- 
Table 6 Mean error (bias), standard deviation of error, $\mathrm{R}^{2}$ and RMSE for Composite and Satellite estimates relative to terrestrial estimates, by farm.

\begin{tabular}{|c|c|c|c|c|c|}
\hline Farm & Dataset & Bias & Standard deviation of error & $\mathbf{R}^{2}$ & RMSE \\
\hline A & Satellite & -23 & 311 & 0.594 & 312 \\
\hline$A$ & Composite & 20 & 284 & 0.654 & 285 \\
\hline$A$ & Satellite-high & -283 & 314 & 0.231 & 422 \\
\hline$A$ & Composite-high & -171 & 303 & 0.364 & 347 \\
\hline $\mathrm{B}$ & Satellite & -97 & 267 & 0.796 & 284 \\
\hline $\mathrm{B}$ & Composite & -33 & 251 & 0.819 & 253 \\
\hline $\mathrm{B}$ & Satellite-high & -283 & 269 & 0.420 & 390 \\
\hline $\mathrm{B}$ & Composite-high & -103 & 291 & 0.443 & 308 \\
\hline $\mathrm{C}$ & Satellite & -62 & 261 & 0.602 & 268 \\
\hline $\mathrm{C}$ & Composite & -44 & 256 & 0.616 & 259 \\
\hline $\mathrm{C}$ & Satellite-high & -256 & 226 & 0.251 & 341 \\
\hline C & Composite-high & -205 & 230 & 0.333 & 308 \\
\hline $\mathrm{D}$ & Satellite & -76 & 401 & 0.609 & 408 \\
\hline $\mathrm{D}$ & Composite & -11 & 378 & 0.643 & 378 \\
\hline $\mathrm{D}$ & Satellite-high & -340 & 412 & 0.189 & 534 \\
\hline $\mathrm{D}$ & Composite-high & -197 & 431 & 0.210 & 473 \\
\hline$E$ & Satellite & 14 & 272 & 0.721 & 272 \\
\hline$E$ & Composite & 59 & 261 & 0.725 & 267 \\
\hline$E$ & Satellite-high & -201 & 241 & 0.256 & 313 \\
\hline$E$ & Composite-high & -80 & 283 & 0.296 & 293 \\
\hline
\end{tabular}

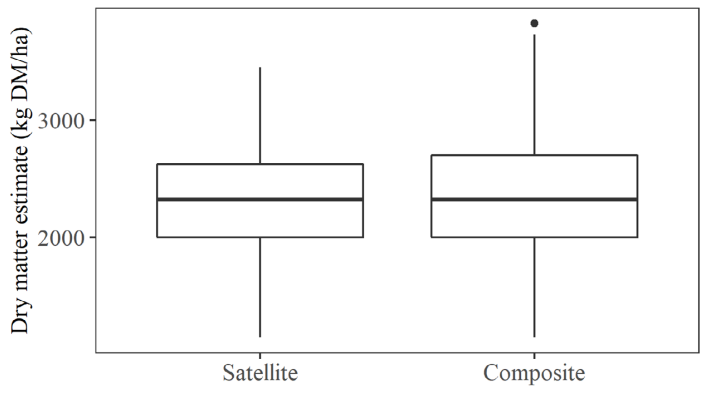

Figure 3 Boxplots showing the distribution of dry matter estimates by source.

High), which - given the overall bias in Composite is only $-9 \mathrm{~kg} \mathrm{DM} / \mathrm{ha}$ - suggests a small upward bias in estimates for the lower range of ground truth values.

The RMSE is a measure of accuracy and is thus affected by both bias and precision (the latter is measured by the standard deviation of error). In this overall measure, the Composite and Composite-high datasets outperform their Satellite-only counterparts. To provide some context for the RMSE results (Satellite: $334 \mathrm{~kg} \mathrm{DM} / \mathrm{ha}$, Composite: $309 \mathrm{~kg} \mathrm{DM} / \mathrm{ha}$ ), King et al. (2010) reported RMSE ranging from 441 to $773 \mathrm{~kg} \mathrm{DM} / \mathrm{ha}$ across five regions of New Zealand for the rising plate meter, and from 520 to $668 \mathrm{~kg} \mathrm{DM} /$ ha for the C-Dax Pasture Meter. This comparison used pasture cuts as a baseline, while our investigation used plate meter and visual observations, so the results are not directly comparable (given each source has its own errors).

Taken as a whole, the results suggest that the incorporation of a growth model can improve the accuracy of satellite biomass estimation when those estimates would otherwise be affected by saturation, and thus can also improve the overall accuracy of satellite biomass estimation. A survey of pasture management specialists showed that high accuracy was regarded as a "need to have" in a pasture measurement device by $84 \%$ of participants (Eastwood \& Dela Rue 2017). Although the accuracy in the current work falls outside the desired $\pm 200 \mathrm{~kg} \mathrm{DM} / \mathrm{ha}$ quoted in that study, this desire for accurate measurements suggests that improvement in accuracy is still a worthwhile aim. Furthermore, for farmers who run high pasture covers, there could be more value than conveyed in this statistical evaluation in mitigating saturation such that those higher paddocks could be more accurately ranked. Future work could investigate this.

The next step in working with the pasture growth model could take advantage of the fact that modelled growth estimates are available every day, regardless 
of the presence of a satellite estimate. On days where there was no satellite measurement available for a given farm - whether due to interference, hardware failure, or no satellites passing overhead - a modelled set of pasture estimates could be supplied to the customer, as proposed in Romera et al. (2013). This option would improve the cadence of pasture measurements, which is limited by the presence of overcast skies in a purely satellite-based system. In the survey by Eastwood \& Dela Rue (2017), weekly measurements of pasture during high-growth periods were regarded as a "need to have" by $90 \%$ of participants, which further motivates such a development.

The data-cleaning methods described in this process are currently somewhat manual in nature but work is in progress to utilise PGF predictions and/or further image analysis in an automated system to identify usable satellite images.

\section{Conclusions/Practical implications/Relevance}

On the data from the farms examined in this investigation, the incorporation of the PGF model with satellite estimations resulted in improved accuracy overall, relative to using purely satellite data. Additionally, the dataset that incorporated growth model data was able to estimate high-biomass ground truth measurements with substantially reduced bias compared to the purely satellite-based system.

This mitigation of the satellite saturation effect would enable the use of satellite pasture measurement for those farmers for whom saturation had previously made it an unviable option (some SPACE customers were satisfied with knowing the saturation phenomenon existed, and measuring a subset of their paddocks manually, while others found saturation made the system unviable to them), and enhance the accuracy of the system for current users.

Improved pasture measurement accuracy enables more timely and accurate management decisions, which in turn result in more efficient use of pasture and more profitable farming operations.

\section{ACKNOWLEDGEMENTS}

Thanks to the technical teams at DairyNZ Ltd, and at Owl Farm, for collecting some of the data used in this investigation. Thanks also to the LIC SPACE ${ }^{\mathrm{TM}}$ team for data collection and advice during the project. SPACE ${ }^{\mathrm{TM}}$ is a commercial product of LIC. The Rezare PGF is a product licensed by Rezare Systems Ltd from DairyNZ. DairyNZ and the Ministry for Primary Industries through the Primary Growth Partnership have funded the pasture growth forecasting model to help farmers increase profitability. The pasture growth model uses climate data supplied by NIWA.

\section{REFERENCES}

Ali I, Cawkwell F, Dwyer E, Barrett B, Green S. 2016. Satellite remote sensing of grasslands: from observation to management. Journal of Plant Ecology 9: 649-671. https://doi.org/10.1093/jpe/rtw005

Anderson G, McNaughton L. 2018. Validation of a satellite pasture measurement system. Proceedings of the 8th Australasian Dairy Science Symposium. Palmerston North, New Zealand.

Beukes PC, McCarthy S, Wims CM, Gregorini P, Romera AJ. 2019. Regular estimates of herbage mass can improve profitability of pasture-based dairy systems. Animal Production Science 59: 359-367. https://doi.org/10.1071/AN17166

Chapman D, McCarthy S, Kay J. 2014. Hidden dollars in grazing management: getting the most profit from your pastures. Proceedings of the South Island Dairy Event, Invercargill, New Zealand. SIDE Secretariat, Lincoln University, Christchurch, New Zealand.

Eastwood CR, Dela Rue BT. 2017. Identification of operational performance attributes for pasture measuring devices. Journal of New Zealand Grasslands 79: 217-222. https://doi.org/10.33584/ jnzg.2017.79.532

ESA. 2020. User Guides - Sentinel-2 MSI - Level-2 Processing - Sentinel Online. Retrieved 1 October 2020 from: https://sentinel.esa.int/web/sentinel/userguides/sentinel-2-msi/processing-levels/level-2

Gu Y, Wylie BK, Howard DM, Phuyal KP, Ji L. 2013. NDVI saturation adjustment: A new approach for improving cropland performance estimates in the Greater Platte River Basin, USA. Ecological Indicators 30: 1-6. https://doi.org/10.1016/j. ecolind.2013.01.041

Huete AR, HuiQing Liu, Leeuwen WJD van. 1997. The use of vegetation indices in forested regions: issues of linearity and saturation. IGARSS'97. 1997 IEEE International Geoscience and Remote Sensing Symposium Proceedings. Remote Sensing - A Scientific Vision for Sustainable Development.

King WMcG, Rennie GM, Dalley DE, Dynes RA, Upsdell MP. 2010. Pasture mass estimation by the C-DAX pasture meter: regional calibrations for New Zealand. Proceedings of the 4th Australasian Dairy Science Symposium: 233-238.

LIC. 2020. Livestock Improvement Corporation $S P A C E^{T M}$ product web page. Retrieved 21 September 2020 from: https://www.lic.co.nz/products-andservices/space/

Mata G, Purdie N, Handcock RN, Dalley D, Ota N, Rossi L. 2011. Validating satellite monitoring of dairy pastures in Canterbury with Lincoln University Dairy Farm and commercial farm data. Proceedings of the New Zealand Grassland Association 73: 109114. https://doi.org/10.33584/jnzg.2011.73.2840 
Mutanga O, Skidmore AK. 2004. Narrow band vegetation indices overcome the saturation problem in biomass estimation. International Journal of Remote Sensing 25: 3999-4014. https://doi.org/10.1 080/01431160310001654923

Planet. 2018. Planet Surface Reflectance Product. Retrieved 8 May 2019 from: https://assets.planet. com/marketing/PDF/Planet_Surface_Reflectance Technical_White_Paper.pdf
Planet. 2020. Planet Combined Imagery Product Specifications. Retrieved 25 March 2020 from: https://assets.planet.com/docs/Planet_Combined Imagery_Product_Specs_letter_screen.pdf

Romera A, Beukes P, Clark D, Clark C, Tait A. 2013. Pasture growth model to assist management on dairy farms: Testing the concept with farmers. Grassland Science 59: 20-29. https://doi.org/10.1111/grs.12009

Woodward SJR, Rollo MD. 2002. Why pasture growth prediction is difficult. Agronomy 32: 17-26. 